\title{
UMA REFLEXÃO CRÍTICA SOBRE A TEORIA SOCIOLINGUÍSTICA
}

\section{(A critical reflection on the sociolinguistic theory)}

\author{
Roberto Gomes Camacho \\ (Universidade Estadual Paulista - São José do Rio Preto
}

\begin{abstract}
Resumo: Um dos postulados da linguística do início do século XX é o de que o objeto da linguística deveria identificar-se com a parte homogênea dos fenômenos observáveis. $\mathrm{Na}$ segunda metade desse século, a sociolinguística representou uma ruptura significativa com o formalismo teórico mediante a introdução do conceito de variável linguística, mas, ao mesmo tempo, dele se aproximou ao adotar o conceito de regra variável. Este trabalho pretende discutir criticamente essa posição encarecendo a necessidade de repropor mais plenamente o falante enquanto agente condutor de seu próprio discurso e, consequentemente, a noção de variável linguística como o espaço privilegiado da construção do significado social da linguagem. Palavras-chave: sociolinguística; regra variável; axioma da categoricidade; formalismo; funcionalismo.
\end{abstract}

Abstract: One of the postulates of the language of the early twentieth century is that the object of linguistics should be identified with the homogeneous part of the observable phenomena. In the second half of this century, sociolinguistics represented a significant break with the theoretical formalism by introducing the concept of linguistic variable, but at the same time, it got closed do it by adopting the concept of variable rule. This paper aims to discuss this position critically by enhancing the need for re-propose more fully the speaker as an agent driving his own speech and therefore the concept of linguistic variable as the privileged space of the construction of the social significance of language.

Key-words: sociolinguistics; variable rule; categoricity axiom; formalism; functionalism.

\section{INTRODUÇÃO}

A universalidade e a ubiquidade da variação deveriam sugerir que sua existência é motivada pela satisfação de algum tipo de necessidade humana. Paradoxalmente, entretanto, a espécie humana nega a existência da variação e onde quer que ela ocorra faz o maior esforço para reduzir seus efeitos, como se exorcizasse uma criatura indesejável, como se reconhecer sua existência equivalesse a reconhecer uma culpa que merece expiação. 
O drama que transborda dessa relação finca suas raízes mais primitivas no mito bíblico da Torre de Babel, já que, como se sabe, é como uma punição divina que o Livro do Gênesis trata a diversidade de linguagem. Por um lado, a construção de uma torre suficientemente alta para desafiar a autoridade de Deus aponta simbolicamente para o desejo humano, o mesmo que move Adão e Eva, de ser agente de manipulação do próprio destino. Mas, por outro, o mito da Torre de Babel representa também o símbolo da submissão, mediante a imposição por Deus do castigo da diversidade linguística. Um claro indício do poder e da autoridade divina, o castigo da diversidade representa a forma de minar o poder das criaturas mortais mediante a extinção de sua capacidade de comunicação irrestrita entre seus semelhantes.

Como há uma dificuldade amplamente aceita de se reconhecer a variação, parece que essa dificuldade tem essa base emocional primordial, arraigada na psique do homem, que se traduz na memória de um castigo ancestral, onipresente, própria da circularidade do tempo mítico. Entende Chambers (1995: 209) que essa face obscura explica em grande parte por que, nas culturas ocidentais, ou pelo menos, judaico-cristãs, numerosas instituições têm como uma de suas funções primárias ou secundárias a redução da diversidade linguística em favor do dialeto padrão. Estão aí para provar os dicionários prescritivos, as gramáticas escolares, as autoridades institucionalizadas.

A ideia abstrata dessa disfuncionalidade grudada na diversidade preserva outra relação relevante com o mito ancestral de explicação da diversidade por expiação: Chambers (1995) debita a disfuncionalidade da variação a relações de poder em situações diversas, cujo traço essencial, a desigualdade dos participantes, é um fator crucial na interação, a mesma relação que o mito instaura entre deuses e mortais.

Esse valor é o mesmo que se observa nas estratégias da elite de instalar seu próprio dialeto como o correto em detrimento das demais variedades. O modo de constituição que fortalece essa variedade como instrumento de poder toma a forma de dicionários, gramáticas e guias de uso em que as preferências linguísticas de um segmento da comunidade são promulgadas como modelo de correção. A legislação que a promulga é o modo como ela é imposta como norma em aparelhos de controle do estado, como governo, meios de comunicação e educação. A negação de conflitos na área da lin- 
guagem parece estar de acordo com a negação de conflitos sociais em geral, gerada por fatores de ordem histórica, sócio-cultural e étnica.

Não é, entretanto, exclusivamente no âmbito da fixação e da defesa de uma norma prescritiva que o processo ideológico tende a interferir no domínio da linguagem. A teoria da linguagem pode basear-se, ela mesma, em certos valores fundamentais, que confinam com os limites do conteúdo ideológico e apresentar, nesse caso, um caráter curiosamente normativo, ainda que o rejeite por princípio. Se, com efeito, procurarmos avaliar a contribuição que deu a linguística para mudar essa concepção, os resultados não ultrapassam a linha do alegado critério de cientificidade, mediante o qual é comum opor a linguística à gramática normativa sobre a base da dicotomia descritivismo/prescritivismo.

Mais grave ainda é perceber que a própria concepção de linguagem desenvolvida recentemente por nós linguistas não tem um sentido diametralmente oposto ao da concepção normativa desenvolvido pelos gramáticos. No âmbito das correntes teóricas mais bem sucedidas do século XX, a ideia de língua corresponde ao mesmo fenômeno homogêneo, fechado em si mesmo, imutável e desligado do contexto social que propõem para si as instituições responsáveis pelo ensino da língua materna.

Que contribuição a sociolinguística deu para romper com esse movimento epistemológico é o tema que pretendo desenvolver mediante a discussão das relações entre a sociolinguística variacionista e as outras correntes mais bem sucedidas na história recente da linguística, que identificam o objeto da linguística com a parte homogênea dos fenômenos observáveis. Outra questão crucial que pretendo examinar é o modo como a sociolinguística variacionista representou, num momento inicial, uma ruptura significativa com o tipo formalista de tratamento teórico mediante a introdução do conceito de variável linguística e, ao mesmo tempo, dele se aproximou ao adotar o formalismo gerativista com o advento da noção de regra variável.

\section{Ponto de vista e idealização}

É notório que a atitude prescritiva, que motiva a sociedade para a erradicação da variação, foi sistematicamente rejeitada pela linguística contemporânea, cuja natureza científica apela para princípios descritivos 
puros, onde imperam a imparcialidade e a objetividade que Martinet tão bem enfatiza. Observe a seguinte citação:

Como o objeto dessa ciência constitui uma atividade humana, é grande a tentação de abandonar o domínio da observação imparcial para recomendar determinado comportamento, de deixar de notar o que realmente se diz para passar a recomendar o que deve dizer-se. A dificuldade de distinguir a linguística científica da gramática normativa lembra a de extrair da moral uma autêntica ciência dos costumes (Martinet 1972: 3).

É o próprio Martinet (1972) quem formula o princípio epistemológico de que uma teoria científica deve necessariamente efetuar uma seleção entre os elementos da realidade que pretende descrever com base no paradoxo entre a infinita complexidade dos fenômenos da realidade a ser descrita e a natureza necessariamente finita de qualquer descrição científica. Essa natureza paradoxal da relação entre ciência e realidade parece aumentar tanto em dimensão, quando se trata de descrever e explicar os fenômenos da linguagem, que acaba por pôr em dúvida a possibilidade de delimitar um objeto específico de estudos.

É suficientemente reconhecido que a dificuldade no enfrentamento dessa questão já era francamente admitida pelo próprio fundador da linguística, Ferdinand de Saussure, ao alegar que "outras ciências trabalham com objetos dados previamente e que se podem considerar, em seguida, de vários pontos de vista; em nosso campo nada de semelhante ocorre (...) Bem longe de dizer que o objeto precede o ponto de vista... é o ponto de vista que cria o objeto" (Saussure 1977 15)

Essa necessidade de descrever a linguagem sob um ponto de vista de modo a incluir alguns aspectos do fenômeno e excluir outros é contraditório com o texto acima citado de Martinet. Se o investigador opera uma seleção entre os fenômenos empíricos observáveis, segue-se obviamente que ele não é capaz de apreender "o que realmente se diz", mas o que é autorizado pelo recorte metodológico, uma parte da realidade; deduz-se que uma teoria assim constituída pode estar longe de constituir uma autêntica ciência dos costumes e acabar sendo, antes, uma teoria da moral, ou alguma coisa próxima de uma atitude normativa.

Ao buscar um objeto de estudos bem delimitado e definido, Saussure idealiza a criatura no próprio ato de criação. A língua saussureana é, em última análise, uma essência que representa exatamente a subordinação 
do objeto a uma determinada perspectiva metodológica. Ao distinguir a língua da fala, Saussure separa o que é geral e social do que é particular e exclusivamente individual. Esse gesto nítido de idealização, que se completa na noção de sistema de relações, cria um objeto científico apartado da rede de relações sociais que constitui o discurso. Separando, além disso, o que é essencial, interno ao sistema linguístico, do que é acessório e acidental próprio do discurso e externo ao sistema, Saussure cria um objeto de estudos de natureza estritamente linguística.

A posição de Chomsky, que, em vários aspectos, revolucionou na década de 60, a teoria da linguagem, pouco difere da concepção saussureana no que se refere exclusivamente à delimitação do objeto. A idealização operada por Saussure se completa com a noção de objeto de estudos desenvolvida por Chomsky, centrada na competência em oposição ao desempenho, perfeitamente observável na citação seguinte:

(...) um falante-ouvinte ideal, situado numa comunidade completamente homogênea, que conhece perfeitamente a sua língua e que, ao aplicar o seu conhecimento no uso efetivo, não é afetado por condições gramaticalmente irrelevantes, tais como limitações de memória, distrações, desvios de atenção e de interesse, e erros (casuais e característicos) (CHOMSKY 1975: 83).

A atividade real e concreta de linguagem, e que de fato a constitui como fenômeno observável, foi mantida no exterior dos limites do objeto de estudos, sob o nome não mais de fala, mas de desempenho e seu enfoque só seria possível a partir do esclarecimento das regras da competência. Nesse caso específico, o falante é identificado como o sujeito cartesiano, lógico e universal, abstraído das relações sociais que estabelece com seu interlocutor no processo de interação verbal.

A idealização dos dois paradigmas mais bem sucedidos no século $\mathrm{XX}-\mathrm{o}$ estruturalismo e o gerativismo - adotada como procedimento epistemológico resultou de uma versão muito forte do que Chambers denomina 'axioma da categoricidade', segundo o qual os dados de base para a análise linguística deveriam ser regularizados de modo a eliminar a variabilidade de fato existente na linguagem enquanto fenômeno real (cf. Chambers 1996).

Uma das premissas que dão suporte a esse axioma é que seria necessário abstrair a linguagem da variação do mundo real para torná-la coerente e controlável e o melhor caminho para isso é, segundo Joos (1950 apud Chambers 1996) aproximar a linguística da matemática, para a qual a inconsistência 
é, por definição, impossível. Assim, para ele, a linguística se identificaria com um sentido extremo de uma mecânica quântica, que exclui toda a possibilidade de gradação infinitesimal em proveito de unidades unicamente discretas e descontínuas. Setores inteiros de estudos linguísticos, que vão da dialetologia à estilística, ficam completamente excluídos da concepção monolítica de linguagem, que ainda hoje as teorias formalistas sustentam, ou, quando muito, exercem um papel marginal e aplicado. Desse modo, para as duas tendências, a linguagem humana se reduz a um sistema estável, imutável, de formas linguísticas submetidas a uma norma e as leis que governam esse sistema estável são especificamente linguísticas, internas, por estabelecerem ligações entre signos, formas e relações no interior de um sistema fechado (cf. Bakhtin 1979: 68).

Por trás desse reducionismo, acham-se, segundo Bakhtin (1979), os procedimentos práticos e teóricos elaborados para o estudo das línguas mortas que se conservaram em documentos escritos. Desse modo, a abordagem filológica com a qual a linguística moderna do século XX pensava romper é determinante para uma avaliação de todo o pensamento teórico contemporâneo. Assim, a concepção de uma língua isolada, fechada e monológica e desvinculada de seu contexto de uso, corresponde à compreensão passiva que os filólogos tiveram, ao longo da história, de uma língua morta, escrita e estrangeira. Consequentemente, a orientação dos paradigmas dominantes da linguística contemporânea para a criação de um objeto de estudos estável e uniforme, desligado da realidade social, reflete o papel histórico que a palavra estrangeira desempenhou na formação de todas as civilizações.

Apoiando-se em Bakhtin, pode-se afirmar que, ao espírito cartesiano, orientado para a matemática, que caracteriza a posição de Joos, não é a relação do signo com a realidade que interessa, mas a relação do signo com outro no interior de sistemas fechados. A história, deixada para segundo plano por Saussure, é, portanto, um domínio irracional que corrompe a pureza lógica do sistema, cujas unidades linguísticas são os signos matemáticos (Bakhtin 1979).

\section{A ruptura com o axioma da Categoricidade}

A partir da década de 60, com o advento do enfoque variacionista, os sociolinguistas tiveram a preocupação de fornecer evidência da hetero- 
geneidade inerente da linguagem e de demonstrar que a ocorrência de variação é sistemática, regular e ordenada. Considerar a variável como uma unidade estrutural representou uma ruptura com a tradição linguística e um momento de renovação teórico-metodológica.

Não era, todavia, difícil para o idealista ignorar a variação porque, linguisticamente, as sentenças significam a mesma coisa a despeito de que variante seja usada. É por isso que, quando as variantes atraíram a atenção dos linguistas, foram tratadas como se pertencessem a diferentes sistemas linguísticos co-existentes (Fries; Pike 1949 apud Chambers 1996) ou como variantes livres. A noção de sistemas co-existentes se sustenta na ideia de que os falantes teriam acesso a diferentes sistemas gramaticais, o que lhes autorizaria a mudar de um para outro, enquanto a noção de variação livre se assenta no princípio de que as variantes não passariam de flutuação aleatória.

A procura por um objeto homogêneo levou também o estruturalismo a desviar seu foco de atenção para segmentos cada vez menores de linguagem, o que veio a culminar com a introdução do termo idioleto no arcabouço teórico da linguística norte-americana, significando o conjunto de usos de uma mesma língua que um falante faz num determinado momento da interação. Além de ser impossível que um idioleto contivesse o dado homogêneo que o linguista procurava, Labov entende que assumir essa noção como objeto de estudos equivaleria a frustrar de saída um conceito basilar da linguística saussureana e estruturalista em geral, que é o conceito de língua como instituição social.

Mais contundente ainda é a crítica que Labov (1972) dirige à falta de coerência teórico-metodológica da dicotomia língua/fala, que lança a teoria estruturalista num instigante paradoxo. Como todos os membros de uma comunidade social compartilham o mesmo conhecimento a respeito da estrutura linguística, a língua acaba sendo um sistema virtual presente no cérebro de todos os falantes. Por isso, seria perfeitamente possível obter os dados necessários para o estudo da "parte social da linguagem" com base no testemunho de qualquer indivíduo falante, quando não no testemunho do próprio pesquisador. Por outro lado, dados sobre a parte individual da linguagem, a fala, só podem ser obtidos através da observação do comportamento linguístico de um grande conjunto de indivíduos. (Labov 1972: 185). É um verdadeiro paradoxo metodológico que o estudo do aspecto social da linguagem dependa da observação do comportamento individual 
e justamente estudo do aspecto individual, da observação da linguagem no contexto social.

No arcabouço gerativista, a questão da variação linguística é, por sua vez, habitualmente contornada mediante recurso aos juízos intuitivos do falante-ouvinte sobre a gramaticalidade das construções. No entanto, a suposta uniformidade dos julgamentos intuitivos identifica apenas variáveis linguísticas já implementadas e que receberam correção social aberta, enquanto a grande maioria das regras linguísticas situa-se num nível bem abaixo de consciência social, sendo, portanto, desprovida de normas sociais abertas que sejam capazes de produzir algum tipo de uniformidade avaliativa (cf. Labov 1972).

Como se vê, as críticas levantadas por Labov eram dirigidas ao parâmetro metodológico tanto da teoria estruturalista quanto da teoria gerativista, mais especificamente à relação entre teoria e dado. Como Chomsky defende a ideia de que uma teoria linguística é subdeterminada pelos dados, é necessário criar medidas de avaliação interna para selecionar a melhor alternativa entre as muitas teorias explanatórias possíveis do mesmo fenômeno.

Contrapondo-se a isso, Labov argumenta que é através do estudo da linguagem em seu contexto social que a quantidade de dados se expande enormemente, oferecendo, assim, meios de decidir que análise é a correta dentre as alternativas possíveis. Para sustentar essa posição, Labov adota o conceito de variação e o insere definitivamente nos estudos linguísticos, como uma propriedade inerente, constitutiva da linguagem:

Os dados empíricos confirmam plenamente a existência de variação e de estruturas heterogêneas nas comunidades linguísticas investigadas. É a existência de qualquer outro tipo de comunidade que pode ser posta em dúvida. (...) chegamos à conclusão nos últimos anos de que essa a situação normal é a de que a heterogeneidade não é apenas comum, mas é também o resultado natural de fatores linguísticos básicos. Postulamos que disfuncional seria a ausência de mudança de estilo e de sistemas multi-estratificados de comunicação (Labov 1972: 203) (tradução minha)

A alternativa teórica introduzida por Labov para resolver os problemas da estrutura linguística incluiu, em primeiro lugar, a concepção de que o sistema linguístico, inerentemente variável, é constituído pelo conjunto das formas manifestadas na situação social por falantes em processo real de co- 
municação. Nessa perspectiva, a análise da língua, assim concebida, envolve a adoção de um conjunto de fatores não apenas linguísticos, mas também extralinguísticos como os de natureza social e estilística. Isso significa adotar a concepção de que operam na linguagem motivações em competição (DU BOIS, 1985) de natureza interna e externa, que participam ativamente da aplicação de uma regra, favorecendo-a ou desfavorecendo-a.

A linguagem é estudada no interior da comunidade de fala, constituída por subconjuntos de falantes, cujo repertório verbal revela a existência de formas que se correlacionam a diferentes tipos de padrões sociais. Tais padrões emergem como pequenas diferenças no comportamento linguístico que fornecem ao ouvinte uma grande quantidade de informação qualitativa. Uma das tarefas da sociolinguística laboviana é reduzir tal informação qualitativa a um conjunto ordenado de dados quantitativos.

Um exemplo clássico de uma variação estável nessa fase inicial é a variação entre presença e ausência de velar final no morfema do gerúndio em inglês (-ing). Em todos os contextos, os membros da comunidade são diferenciados pela frequência com que usam a variante de prestígio (presença da velar), o que fica evidente na distribuição quantitativa, segundo a qual os índices mais altos e mais baixos estão diretamente correlacionados respectivamente a posições mais altas e mais baixas na escala sócio-econômica.

Paralelamente a essa distribuição social, o uso da variante velar identifica também diferentes grupos sociais quanto ao grau de formalidade da situação discursiva, na medida em que quanto maior a frequência da alternativa de prestígio tanto maior o grau de formalidade da situação e vice-versa. Como não são restrições de natureza linguística que favorecem ou desfavorecem a supressão da velar, mas restrições de natureza extralinguística, as motivações em competição são, nesse caso, externas ao sistema linguístico.

A unidade linguística de qualquer nível de análise, que até então tinha sido invariável, discreta e qualitativa, passa a ser variável, contínua e quantitativa (Labov 1966). É variável porque é realizada diferentemente em diferentes circunstâncias; é contínua porque certas alternativas recebem significação social conforme a distância ou a diferenciação fonética em relação à forma padrão; é quantitativa porque a variável é determinada pela frequência relativa de suas variantes. 


\section{O CONCEITO DE REGRA VARIÁVEL}

O advento do conceito de regra variável (Labov 1969) alterou de modo muito significativo a interpretação do conceito de variável linguística. Em essência, o conceito de regra variável expandiu e redefiniu a noção de opcionalidade da linguística gerativa para incluir restrições linguísticas e sociais em sua natureza variável.

Ao lidar com processos de intersecção entre gramática e fonologia, como o fenômeno de simplificação de grupos consonantais, comuns no inglês afro-americano, como os do tipo bold x bol' e rolled x roll', Labov (1972) menciona uma inadequação da noção de regra opcional. Alega que grupos consonantais em que o morfema de pretérito estiver envolvido, como o de roll-ed, de acordo com a fórmula $\mathrm{CVC}+\mathrm{D}$, não podem ser tratados do mesmo modo que os grupos consonantais envolvidos em bold, de acordo com a fórmula CVCD, que não envolvem risco de perda de informação gramatical. Em razão de motivações internas em competição, as formas envolvendo morfema de pretérito são simplificadas com menos frequência estatística que as formas envolvendo apenas perda de segmento fonológico

As teorias linguísticas convencionais - o estruturalismo e o gerativismo - não teriam critérios nem meios para o enquadramento formal desse fenômeno variável por tratarem a alternância entre bold e rolled como variação livre ou regra opcional. Esse tipo de tratamento implica em ignorar o fato de que as formas de pretérito são simplificadas menos frequentemente que as que não envolvem esse valor semântico (LABOV 1972: 189-90).

Para sustentar a ideia de que fenômenos reais, observáveis nos dados empíricos coletados na comunidade de fala, é que devem constituir o verdadeiro substrato da análise linguística, Labov (1969) adota o formalismo da gramática gerativa para representar esse tipo de processos de variação. Essa metodologia inclui inovações na regra de reescrita do paradigma chomskiano, como a adoção de colchetes angulares para referir-se a variáveis dependentes e expoentes gregos para indicar o grau de influência de um condicionamento sobre o outro, transformando, portanto, na representação formal, a noção de regra opcional em regra variável.

Apesar das substanciais descobertas de regularidades sob a égide da noção de regra variável, esse conceito entrou rapidamente no fogo cerrado da crítica, que, em vez de arrefecer, ampliou ainda mais seu poder de com- 
bustão quando, na década de 70, o conceito foi estendido aos fenômenos sintáticos com os mesmos métodos aplicados aos fenômenos fonológicos. Esse momento representou a primeira grande crise no estatuto metodológico da teoria variacionista em razão de forte reação, provocada por Lavandera (1978), Romaine (1981) e García (1985). O ataque de Romaine mirou o aspecto indutivista da teoria, enquanto os de Lavandera e García, o estatuto teórico da regra variável, quando aplicada à sintaxe.

A polêmica entre Lavandera (1978) e Labov (1978) se resume à questão da real equivalência semântica entre duas variantes sintáticas. Na realidade, a noção de equivalência semântica implicaria uma redução muito drástica da noção de significado referencial, se a sociolinguística insistisse em manter o princípio de que duas formas alternativas são variantes se representarem o mesmo significado no mesmo contexto de ocorrência. Em vez de operar com essa concepção extremamente limitada de significado, Lavandera (1978) propõe substituir o conceito de equivalência semântica pelo de comparabililidade funcional.

Uma segunda polêmica foi engatilhada pelo trabalho de Kay \& McDaniel (1979); seguiram-se a réplica de Sankoff \& Labov (1980) e a tréplica de Kay \& McDaniel (1981). A principal crítica da dupla se dirige à incompatibilidade entre o modelo gerativista e o variacionista, que trabalham, respectivamente, nos níveis da competência e do desempenho. Como a regra variável é probabilisticamente regida, é difícil inseri-la adequadamente num modelo de competência. A principal falha do enfoque variacionista está, para Kay \& McDaniel (1979) e para Romaine (1981), na adoção do formalismo das regras gerativas como um mecanismo puramente descritivo, sem considerar seriamente suas implicações teóricas.

\section{A Regra VARiável COMO CONCEITO FORMAL}

Um ponto crucial do conceito de regra variável que foi acaloradamente debatido por Lavandera (1978), Labov (1978), Romaine (1980), Garcia (1985), Sankoff (1988) é o grau em que as variantes de uma variável sintática são realmente diferentes maneiras de dizer a mesma coisa, como se dá claramente com alternativas fonológicas.

Segundo Garcia (1985: 193), o formalismo gerativista adotado é cego aos dois tipos distintos de variação, um relacionado ao contexto linguístico 
local (como alternativa à opcionalidade gerativa) e o outro relacionado a variáveis sociais de natureza extralinguística, como alternativa para a noção estruturalista de variação livre alofônica. As implicações teóricas dessa identificação entre esses dois tipos incompatíveis de fenômenos tiveram sua importância claramente explicitada somente quando a regra variável se tornou a ferramenta analítica com o qual seria possível descrever qualquer tipo de variação sociolinguística, independentemente do fenômeno em análise.

A identificação entre dois tipos de variabilidade é destituída de problemas se, permanecendo no nível fonológico, o linguista contrastar a variação livre alofônica (correlacionada a fatores extralinguísticos) com outro tipo de variabilidade, ou seja, frequência variável de ocorrência, condicionada pelo contexto sintagmático. A arbitrariedade da relação entre contexto linguístico e não-linguístico está no fato de que a variação alofônica é destituída de significado e, portanto, não representa uma escolha significativa do falante. Não há uma conexão causal entre a natureza intrínseca de um marcador, como a centralização do ditongo na variedade insular de Martha's Vineyard $^{1}$, e o grupo social particular que o caracteriza, já que, se por definição nenhum valor comunicativo é anexado a alofones em variação livre, estes podem adquirir o valor de marcadores sociais, que permitem identificar diferentes comunidades sociais.

Quando se trata, entretanto, de unidades fonológicas ou "êmicas" o fenômeno se torna radicalmente diferente de unidades não-fonológicas ou "éticas", como as discutidas acima. A frequência relativa de ocorrência de diferentes fonemas em diferentes contextos não é arbitrária: o fato de certo contexto favorecer mais uma alternativa que outra pode refletir princípios universais, e o que permanece arbitrário é o grau específico em que ocorre o processo em correlação com diferentes parâmetros extralinguísticos, ou seja, a exata relevância de cada parâmetro linguístico para cada grupo social.

O que seria, portanto, teoricamente problemático para a noção de regra variável é o hibridismo teórico que ela implica. Espera-se que o

1. No início dos anos 60, Labov (1972) testemunhou a existência de um grupo engajado na economia pesqueira local da ilha Martha's Vineyard que resistia sistematicamente à incursão de turistas e residentes de veraneio do continente. A elevação do núcleo dos ditongos / ay / e / aw /, que marcava originalmente uma diferença geográfica local, passou a representar um símbolo de identidade sócio-cultural. 
mesmo mecanismo analítico formal dê conta de dois tipos diferentes de frequência: as que são motivadas pelo contexto linguístico em que as unidades em análise aparecem e, portanto, são dele dependentes; as que não são motivadas pelo contexto linguístico e por isso podem caracterizar diferentes grupos sociais.

Confiantes na gramática gerativa dos anos 60, que usava o mesmo formalismo das regras de reescrita para a fonologia e para a sintaxe, os variacionistas não viram problema em estender as regras para acima e para além da fonologia. Se a fonologia, a morfologia e a sintaxe eram todas formalizadas pela gramática gerativa mediante regras de reescrita, não haveria obstáculo algum para que o condicionamento variável da opcionalidade fosse estendido a outros segmentos da gramática como o sintático.

Entretanto, alega Garcia (1985: 199), a analogia mais adequada a ser feita com a variação sintática não é a variante livre alofônica, que indica significação social, mas a distribuição fonológica não-aleatória, sistemicamente motivada, de unidades fonologicamente distintivas. O próprio conceito de variação sintática, entendido como formas diferentes de dizer a mesma coisa, é, na visão de Garcia (1985: 199), um equívoco fundamental por identificar a alternância entre unidades significativas distintas com a variação livre alofônica. Prova desse equívoco é que, para o tipo de variação sintática com que a sociolinguística passou a trabalhar, o contexto linguístico acabou sendo de longe muito mais importante que fatores extralinguísticos, precisamente o reverso do que ocorreu com os primeiros estudos de variação fonética, que têm na centralização dos ditongos da Ilha Martha's Vineyard um exemplo paradigmático.

Para ilustrar a dificuldade de lidar com o significado em variáveis sintáticas, Fasold (1991) fornece um caso exemplar desenvolvido por Jacobson (1989 apud Fasold 1991:13). O autor citado analisa a alternância entre complementos do tipo to + infinitivo e of + verbo + -ing em inglês e mostra que em decision to do it ou permission to do it o uso do complemento com to + infinitivo é invariavelmente usado, mas com probability, é usada apenas a alternativa of + verbo + -ing. A explicação é a de que tanto a probabilidade quanto o fazer em si está absolutamente fora do âmbito da responsabilidade de qualquer indivíduo particular.

Por outro lado, o fato de ser possível falar chance to do it ou chance of doing it parece fornecer um espaço privilegiado para a análise da variação 
sintática. Entretanto, o autor argumenta que as alternativas não são diferentes maneiras de dizer a mesma coisa. Quando um participante do ato de fala estiver envolvido, seria natural dizer my chance to achieve it e nunca my chance of achieving it; entretanto, num exemplo como there was no chance of making further progress, em que chance e fazer progresso são apresentados como desligados da ação dos participantes da interação, apenas a alternativa com gerúndio é licenciada e nunca a com infinitivo. Assim, as duas maneiras de usar chance com um complemento não parecem constituir modos de dizer a mesma coisa; são, na realidade, diferentes escolhas do falante ${ }^{2}$.

Garcia (1985) sugere compartilhar a mesma opinião ao tecer críticas ao modo como Weiner \& Labov (1983) vêem as noções de escolha entre construções passivas e ativas. Um dos objetivos desses autores é apresentar um estudo quantitativo dos fatores que determinam a preferência na seleção de construções passivas sobre as ativas por falantes do inglês e esclarecer a questão qualitativa crucial de quais traços sintáticos e quais traços semânticos do contexto determinam a escolha entre as duas alternativas.

Para Garcia (1985), a falta de clareza que Weiner \& Labov (1983) têm do conceito de "escolha linguística" estaria supostamente arraigada na visão de linguagem que eles compartilham, identificada por Garcia como um comportamento governado por regras. Dessa perspectiva, a tarefa do linguista deveria ser somente descobrir e descrever as regularidades ocultas que "governam" o aparente caos e grau de arbitrariedade do uso de uma língua, uma visão que é altamente compatível com o desejo variacionista de assumir a equivalência linguística de diferentes expressões e dividir a distribuição de formas governadas por regras em categóricas e variáveis.

É justamente esse postulado que, segundo Garcia esvaziaria o termo escolha do conteúdo linguístico que ele implica. O que seria, portanto, sistemática e significativamente abandonado nos estudos variacionistas é justamente o valor comunicativo das alternativas envolvidas, a diferença que elas fazem para o que se diz quando se escolhe uma forma em vez de outra. "Em sociolinguística parece que o FALANTE nunca tem uma escolha, o que é particularmente paradoxal, e especialmente deplorável num enfoque

2. A linguística brasileira não permaneceu impermeável a essa discussão. Dois artigos (OLIVEIRA 1986; POSSENTI 1986), que resultaram de apresentações num simpósio da ABRALIN intitulado A questão da variação linguística, discutem particularmente a relação entre variável, significado e contexto. 
para o qual é supostamente básica a natureza social da linguagem" (Garcia 1985: 220) [tradução minha] $]^{3}$.

Voltando, agora a atenção para as implicações teóricas do formalismo adotado, alguns dos primeiros estudos sobre regra variável levou alguns pesquisadores (Kay 1978; Kay; McDaniel 1979; ROMAINE 1981) à conclusão de que a análise em regra variável implicava uma comunidade de fala de regra variável em que todos os membros teriam as mesmas regras com as mesmas restrições e as mesmas ordens de restrições. Com efeito, para Labov (1969), o lugar privilegiado da linguagem é a comunidade de fala ou grupo social e, desse modo, o discurso de qualquer grupo social é menos passível de variação que o discurso de qualquer indivíduo. Consequentemente, regras variáveis são aplicáveis a grupos não a indivíduos com base no postulado de que há uma relação isomórfica entre a gramática do indivíduo e a gramática do grupo social.

Pondo ainda mais lenha na fogueira, alega Romaine (1981) que, ironicamente, o paradigma variacionista e a gramática gerativa seriam similares em relação a um aspecto teórico relevante: ainda que por razões teóricas diferentes, a idealização dos dados produzida por Labov, assim como por Chomsky, resulta numa gramática que não descreve o discurso de nenhum indivíduo. Entretanto, na medida em que o paradigma variacionista está interessado em explicar desvios individuais do comportamento coletivo, a existência de variação idioletal e o isomorfismo entre o comportamento do indivíduo no grupo e o do grupo como um todo é muito mais motivo de embaraços para o paradigma variacionista do que para o paradigma gerativista (ROMAINE 1981: 102).

É possível incorporar as críticas de Romaine ao coro dos que objetam que, contrariamente a algumas implicações dos textos de Labov, a introdução do conceito de regra variável não representou apenas um adendo à gramática gerativa, mas um afastamento tão radical dela que não pode ser concebido dentro de seu arcabouço teórico ortodoxo. Esse tipo de formulação acaba produzindo apenas confusão conceitual na medida em

3. Essa crítica poderia ser debitada à concepção funcionalista de Garcia que, segundo Du Bois (1985) a inscreveria no rol dos funcionalistas transparentes, que assumem o princípio de que fatores sintáticos aparentemente autônomos constituem, na realidade, os resultados transparentes dos objetivos funcionais do falante; desse modo, as únicas forças que governam a "sintaxe" são as forças positivas da linguística externa, exemplificadas por Du Bois como mecanismos de processamento de base biológica, intenções do falante etc (Du Bois 1985). 
que seu proponente pensava estar operando dentro do arcabouço gerativo, quando, na realidade não estava (Kay; McDaniel 1978: 152).

Com efeito, uma teoria formalista, como a gerativa, procuraria especificar que construções são possíveis numa dada língua ou nas línguas em geral com base no conceito de gramaticalidade. Enquanto a regra opcional gerativista foi programada para especificar apenas a possibilidade de haver mais de uma estrutura alternativa em certo ponto da derivação, uma regra variável, por seu lado, foi programada para fazer predições sobre a frequência com que formas alternativas ocorrem sob determinadas condições linguísticas e sociais.

Para Romaine (1981) é difícil entender como uma teoria gramatical, como a variacionista, que lida com a realidade cultural, poderia gerar postulados sobre a realidade psicológica. $\mathrm{Na}$ realidade, o tipo de predições que faz uma gramática gerativa recobre o conhecimento internalizado que os falantes têm de sua língua e, por isso, as predições e explicações não fazem necessariamente referência a nenhum fenômeno do mundo espáciotemporal. Sob certas condições, os postulados que se derivam desse tipo de gramática podem ser testados mediante observações do comportamento linguístico, mas não se referem jamais a nenhum tipo de comportamento humano, como é comum no tratamento variacionista.

A implantação do modelo formal de regra variável teve afinal vida curta motivada pela lenta agonia do modelo governado por regras na própria gramática gerativa. Por um lado, as teorias fonológicas mais recentes buscam explicações mais convincentes em substituição à descrição de processos previstos na fonologia gerativa originalmente proposta por Chomsky \& Halle (1968). Por outro, na sintaxe, se era difícil ver a variação como que relacionada a transformações sintáticas, as próprias transformações perderam a proeminência que tinham no modelo gerativo estendido. A teoria gerativa, ainda no âmbito da Teoria da Regência e da Ligação (Chomsky 1981; 1986), reduziu o aparato transformacional a apenas uma única regra - Mova Alfa com condições muito restritivas de aplicação. Seria difícil e ao mesmo tempo destituído de sentido tentar transplantar regras variáveis sintáticas nessa teoria ou em qualquer outra teoria sintática alternativa. Por isso, a regra variável foi abandonada sem muito alarde pela própria sociolinguística variacionista, talvez por causa de um entendimento implícito dos problemas explanatórios que gerou e das diferentes exigências de teorias da estrutura linguística e teorias do uso, que toquei ligeiramente nesta seção. 
Entretanto, o abandono do conceito de regra variável não desviou a sociolinguística dos trilhos do formalismo adotado na década de $70 . \mathrm{Na}$ realidade, mantendo inalterável a posição assumida no texto de 1983 em parceria com Weiner de que motivações formais são prioritárias em relação às funcionais, Labov (1987) reduziu drasticamente o alcance das explicações funcionais, enumerando uma série de argumentos com contra-exemplos que explicitamente favorecem a autonomia do formal.

E, mais recentemente, ao discutir o caráter funcional da mudança, Labov (1994) retoma essa mesma linha de argumentação. Em face da variação fonológica e morfológica, a hipótese funcional prevê uma tendência do falante para selecionar uma variante ou outra de modo a preservar informação. A maioria dos resultados que discute mostra, ao contrário, que, no discurso corrente, a escolha entre variantes descarta a maximização de informação em favor de efeitos mecânicos, como o condicionamento fonético e a mera repetição de estruturas precedentes. ${ }^{4}$

Tarallo (1990) interpretou positivamente a 'brusca virada' do modelo variacionista: para ele, o princípio da heterogeneidade inerente da linguagem permanece intocável, mas a sociolinguística abre espaço para o linguístico desempenhar um papel maior e o contextual um papel menor. Já García (1981) entende que a virada representou uma retirada estratégica de várias frentes de batalha, antes conquistadas com o sacrifício do componente social. Seguiu-se então um movimento significativo da variável sociolinguística para a simples variável linguística, conforme se observa em Weiner \& Labov (1983), que sugerem claramente que a variação sintática pode não ser motivada de fato nem por fatores sociais nem por fatores funcionais e aproxima a sociolinguística variacionista do estruturalismo autônomo ${ }^{5}$.

4. A relação entre explicações formais e explicações funcionais foi discutida em texto anterior (Camacho 2003).

5. A noção de estruturalismo autônomo foi usada por Du Bois (1985) para referir-se à posição teórica que restringe severamente a conexão do signo com os fatos positivos do mundo externo, ao considerá-lo governado por forças inteiramente internas, onde reinam soberanas as oposições sistemáticas entre os signos no interior do paradigma. 


\section{A recuperação do Sujeito real na metodologia SOCIOLINGUÍSTICA}

Parece-me que a crítica mais grave dirigida por Garcia (1985) à metodologia variacionista é justamente o esvaziamento do falante enquanto agente condutor de seu próprio discurso. Uma nova tendência inaugurada por Eckert (2000) repropõe o conceito de variável linguística, que passa a constituir o espaço privilegiado da construção do significado social da linguagem. Ao reconstruir a trajetória da pesquisa sociolinguística dos últimos 40 anos Eckert (2005) distingue três ciclos de prática analítica, que não devem ser vistas como sobrepostas numa cronologia linear, mas como partes de um todo.

O primeiro ciclo nos estudos variacionistas, lançada pelo estudo de Labov sobre a cidade de Nova York (1966), estabeleceu, como é sabido, uma base sólida para o estudo da variação, mediante o estabelecimento de correlações entre variáveis linguísticas e categorias sociais primárias, como classe sócio-econômica, sexo, idade, escolaridade etc. Os padrões regulares e sistemáticos de co-variação social e linguística levantaram questões sobre relações sociais subjacentes às categorias sociais primárias, o que conduziu ao surgimento do segundo ciclo, caracterizado por estudos etnográficos de populações mais localmente definidas.

Os estudos etnográficos, que caracterizam o segundo ciclo enfocam comunidades menores por períodos de tempo relativamente longos com o objetivo de descobrir as categorias sociais localmente mais salientes. Essas categorias podem ser instanciações locais das categorias primárias que guiam os estudos quantitativos, mas o traço distintivo crucial desse tipo de estudos é a descoberta do lugar dessas categorias na prática social local.

Como um exemplo de que os ciclos não se sobrepõem, Eckert (2005) afirma que a primeira via etnográfica, quantitativamente orientada da variação, aberta por Labov no estudo realizado na ilha Martha's Vineyard, foi depois trilhada por outras pesquisas realizadas na Europa. No enfoque etnográfico de Belfast, Milroy (1980) avançou-o mais ao enfocar comunidades de classe operária e examinar a relação entre engajamento local e uso do vernáculo, correlacionando o uso de variáveis vernaculares locais com a densidade e a multiplicidade da rede de relações sociais do falante.

O terceiro ciclo, que se desenvolveu mais recentemente, centra o foco na variação vista não como o reflexo do lugar social num ponto da escala, 
mas como um recurso para a construção de significado social. Eckert tem justamente se voltado para a necessidade de conectar essas categorias sociais mais abstratas, arraigadas na experiência do falante, com as comunidades imaginárias mais amplas, centrando foco na construção do conceito de comunidade de prática. Uma comunidade de prática é um agregado de pessoas que se juntam para engajar-se em algum empreendimento comum. $\mathrm{Na}$ esteira desse engajamento, a comunidade de prática desenvolve meios para fazer coisas que se traduzem em práticas e essas práticas envolvem a construção de uma orientação compartilhada em relação ao mundo em volta - uma definição tácita que assumem um em relação ao outro e em relação a outras comunidades de prática.

O conceito-chave para o processo de construção é o de prática estilística. Até aqui, nos estudos variacionistas, o estilo tem sido tratado como ajustes à (in) formalidade da situação mediante o uso de variáveis individuais. A face renovada de estilo o identifica com o modo como os falantes combinam variáveis para criar modos distintivos de fala, que fornecem a chave para a construção da identidade. A identidade consiste, por sua vez, em tipos particulares explicitamente localizados na ordem social. Continuamente, os falantes atribuem significado social à variação de um modo consequente, situação que implica certo grau de agentividade, que o trabalho de Eckert (2000) parece querer recuperar.

Eckert (2005) postula que toda variação tem potencial para receber significado social, ainda que nem toda variação seja conscientemente controlada ou mesmo socialmente significativa. A indexação de variáveis fonológicas não é tão transparente quanto, por exemplo, o uso de partículas honoríficas, mas é justamente a fluidez delas que as torna acessíveis a uma grande variedade de propósitos sociais. É necessário haver apenas tempo e continuidade suficientes para convencionar a relação entre uma variável e um significado social. É por essa razão que variáveis estáveis, como a redução de $(-i n g)$ no inglês americano têm significados tão extremamente claros que podem ser referidos como estereótipos, ao passo que variantes representando mudanças em progresso são recursos mais instáveis, mais transitórios e, por isso, mais disponíveis para assumirem significado social. Um contínuo da convencionalização acompanha um contínuo de intencionalidade, num processo que torna o sujeito agente dos processos sociais que constroem sua própria identidade. 


\section{Palavras finais}

Para encerrar, recorro a Du Bois (1985), segundo o qual o grau de preparação de que dispomos para avaliar o significado da teoria linguística deve-se dar a partir de uma perspectiva que vê as gramáticas como sistemas adaptativos e que, portanto, reconhece, em primeiro lugar, a interação entre forças internas e forças externas. Quando as forças que se originam de fenômenos externos penetram o domínio da língua, elas se encontram e interagem com as forças internas.

Dizer que a linguagem é adaptativa, por responder a pressões do contexto externo, implica rejeitar por princípio teorias estruturalistas autônomas, que são limitadas por restringirem a explicação da organização da linguagem apenas às motivações internas. Dizer, por outro lado, que a linguagem é um sistema e que, como tal, tem certo grau de continuidade, implica em rejeitar o arcabouço teórico do funcionalismo transparente, que falha em explicar o funcionamento da linguagem por assumir o princípio de que fatores sintáticos aparentemente autônomos constituem os resultados transparentes dos objetivos funcionais do falante e as únicas forças que governam a sintaxe são as motivações inerentemente externas.

Como alternativa para as versões rigidamente ortodoxas do estruturalismo autônomo e do funcionalismo transparente, Du Bois (1985) propõe a busca de uma síntese, um novo marco teórico que fosse capaz de lidar com a interação entre forças internas e forças externas, assim como com a resolução sistemática da competição que as envolve. A tarefa metodológica inicial, em sua proposta, consiste em construir um arcabouço para uma (sócio) linguística real da fala, que seja capaz de incorporar as descobertas dos estudos mais recentes do discurso real. Parece, então, que, sob essa perspectiva, o entendimento que temos da teoria sociolinguística permite assumir que o terceiro ciclo, na visão de Eckert (2005), é o ponto de vista mais consistente com o postulado de que a linguagem é um sistema adaptativo.

Recebido em agosto de 2009 Aprovado em setembro de 2009 E-mail: camacho@ibilce.unesp.br 


\section{REFERÊNCIAS BIBLIOGRÁFICAS}

Bakhtin, M. (Voloshinov, V.N.). 1979. Marxismo e filosofia da linguagem. Trad. de M. Lahud e Yara F. Vieira. São Paulo: HUCITEC.

Bentivoglio, P. 1987. A variação nos estudos sintáticos. Estudos Linguísticos (Anais de Seminários do GEL). V. 14, Campinas, p. 7-29.

CAмACHO, R.G. 2003. O formal e o funcional na teoria variacionista. In: Roncarati, C.e Abraçado, J. (orgs.). Português brasileiro. Contato linguístico, heterogeneidade e história. Rio de Janeiro: 7Letras, p. 55-65.

CHAmbers, J.K. 1996. Sociolinguistic theory.Linguistic variation and its social significance. Oxford/Cambridge: Blackwell.

Chomsky, N. 1975. Aspectos da teoria da sintaxe. Trad. de J.A. Meireles, E. Raposo. Coimbra: Armênio-Amado Editor. 1981. Lectures on government and binding. Dordrecht: Foris. Barriers. 1986. Cambridge: The MIT Press. \& Halle, M. 1968. The sound pattern of English. New York: Harper and Row.

Du Bors, John W. 1985. Competing motivations. In: Haiman, John (ed.) Iconicity in syntax. Amsterdam/:Philadelphia: John Benjamins, p. 343-65.

ECKERT, P.2000. Linguistic variation as social practice. Oxford: Blackwell. 2005. Variation, convention, and social meaning. Paper presented at the Annual Meeting of the Linguistic Society of America. Oakland CA. Jan 7.

Fasold, R. 1991. The quiet demise of variable rules. American Speech, 66: 3-21, 1991.

García, E. C. 1985. Shifting variation. Lingua, 67: 189-224.

KAY, P. 1978. Variable rules community grammar and linguistic change. In SANKoff, D (ed.) Linguistic variation: models and methods. New York: Academic Press.

, McDaniel, Ch.K. 1979. On the logic of variable rules. Language in society, 8: 151-87.

, McDaniel, Ch.K.1981. On the meaning of variable rules. Language in society, 10: 251-8.

Labov, W. 1966.The social stratification of English in New York City. Washington, D.C.: Center for Applied Linguistics. . 1969. Contraction, deletion and inherent variability of the English copula. Language, 45: 715-62. 
. 1972. Sociolinguistic patterns. Philadelphia: University of Pennsylvania Press.

. 1978. Where does the linguistic variable stop? A response to Beatriz Lavandera. Sociolinguistic Working Papers, 44. Austin, Texas. Southwest Educational Development Laboratory.

. 1987. The overestimation of functionalism. In: DiRven, R., FrIED, V.(eds.) Functionalism in linguistics. Amsterdam/Philadelphia: John Benjamins, p. 311-32.

. 1994. Principles of linguistic change. Vol 1: Internal factors. Oxford/ Cambridge: Basil Blackwell.

LAVANDERA, B.R. 1978. Where does the sociolinguistic variable stop? Language in Society. 7: 171-82.

Martinet, A.1972. Elementos de linguística geral. Lisboa: Sá da Costa.

Oliveira, M. A. 1986. Algumas notas sobre o conceito de variável linguística e sua dimensão nas descrições gramaticais. Boletim da ABRALIN, $8 ; 87-96$.

Possenti, S. 1986. Uma variante é variante de quê? Boletim da ABRALIN, 8: 107-118.

Romaine, S. 1981. The status of variable rules in sociolinguistic theory. Journal of Linguistics. 17: 93-119, 1981.

SANKOFF, D. 1982. Sociolinguistic method and linguistic theory. In: CoHEN, J.J. et al (eds.) Logic, Methodolody and Philosophy of Science VI. Amsterdam: North-Holland, p. 677-89.

SANKOFF, D e LABOv, W. 1979. On the uses of variable rules. Language in society. 8: 189-222.

Saussure, F. de. 1977. Curso de Linguística Geral. São Paulo: Cultrix.

TARAllo, F. A 190. A estrutura na variação: do falante-ouvinte real ao Falante-Ouvinte Real. D.E.L.T.A.. 6/2: 195-222.

Weiner, E. J e LABOv, W. 1983. Constraints on the agentless passive. Journal of Linguistics, 19: 29-58. 